\title{
Functional results and outcomes after repair of proximal hamstring avulsions.
}

\author{
Steven B Cohen \\ Rothman Institute \\ Ashwin Rangavajjula \\ Thomas Jefferson University Medical School \\ Dharmesh Vyas \\ University of Pittsburgh Medical Center \\ James P Bradley \\ Burke and Bradley Orthopedics
}

Follow this and additional works at: https://jdc.jefferson.edu/rothman_institute

Part of the Orthopedics Commons

Let us know how access to this document benefits you

\section{Recommended Citation}

Cohen, Steven B; Rangavajjula, Ashwin; Vyas, Dharmesh; and Bradley, James P, "Functional results and outcomes after repair of proximal hamstring avulsions." (2012). Rothman Institute Faculty Papers. Paper 31.

https://jdc.jefferson.edu/rothman_institute/31

This Article is brought to you for free and open access by the Jefferson Digital Commons. The Jefferson Digital Commons is a service of Thomas Jefferson University's Center for Teaching and Learning (CTL). The Commons is a showcase for Jefferson books and journals, peer-reviewed scholarly publications, unique historical collections from the University archives, and teaching tools. The Jefferson Digital Commons allows researchers and interested readers anywhere in the world to learn about and keep up to date with Jefferson scholarship. This article has been accepted for inclusion in Rothman Institute Faculty Papers by an authorized administrator of the Jefferson Digital Commons. For more information, please contact: JeffersonDigitalCommons@jefferson.edu. 


\title{
As submitted to:
}

\section{The American journal of sports medicine.}

\author{
And later published as: \\ Functional Results and Outcomes after Repair of Proximal \\ Hamstring Avulsions \\ Volume 40, Issue, 9, pp.:2092-8. September 2012 \\ doi: $10.1177 / 0363546512456012$
}

Steven B. Cohen, MD

Associate Professor

Department of Orthopedic Surgery

Thomas Jefferson University

Rothman Institute Orthopedics

Philadelphia, PA

Ashwin Rangavajjula, BS

Thomas Jefferson University Medical School

Philadelphia, PA

Dharmesh Vyas, MD, PhD

Assistant Professor

Department of Orthopedic Surgery

University of Pittsburgh Medical Center

Pittsburgh, PA 
James P. Bradley, MD

Burke and Bradley Orthopedics

Pittsburgh, PA

Investigation performed at Rothman Institute; Philadelphia PA, and University of Pittsburgh Medical Center; Pittsburgh, PA

Key Words: proximal hamstring rupture, proximal hamstring avulsion, proximal hamstring repair

Please address correspondence to:

Steven B. Cohen, MD

Rothman Institute Orthopedics

925 Chestnut Street

Philadelphia, PA 19107

267-339-7812

Fax: 215-503-0580

Steven.cohen@RothmanInstitute.com 


\begin{abstract}
Introduction: The purpose of this study is to assess post-surgical outcomes in active patients after primary repair of acute and chronic proximal hamstring tears. We hypothesized that surgical treatment of both acute and chronic proximal hamstring avulsion injuries would result in improved patient outcomes using validated outcome scores and a hamstring-specific questionnaire, and that operative repair of these injuries results in excellent results with a high level of patient satisfaction, pain relief, and return to function.
\end{abstract}

Methods: Fifty-two patients out of 63 who underwent proximal hamstring repair completed the Lower Extremity Functional (LEFS), a custom LEFS, the Marx Activity Scale, a custom Marx scale, a proximal hamstring score (which combines the sum of the Custom LEFS and Marx) and a proximal hamstring questionnaire with subjective questions. Twenty-six patients were female and 26 were male. The average age at the time of surgery was 47.7years (range: 17-66). In 31 of the patients the right leg was affected, and in 21 the left leg was affected. Forty patients were characterized as having acute repairs and 12 patients had chronic repairs. All patients underwent surgical repair with the similar technique using 5 suture anchors on the ischial tuberosity using a transverse incision. The rehabilitation protocol was also similar with the use of a hip orthosis for 6-8 weeks allowing progressive weight-bearing and range of motion.

Results: The mean follow-up in our study was 33 months (range: 12-76). The mechanism of injury in 28 patients was due to eccentric hip flexion and knee extension in the ipsilateral knee typically caused by a slip and fall accident. One patient's injury was the caused by trauma to the proximal hamstring. In 23 patients hamstring injuries were sports related. Overall, of the 52 patients in our cohort, 51 or $98 \%$ were satisfied with their outcome following surgery. LEFS, Marx, custom LEFS, custom Marx, and proximal hamstring scores for acute patients were $76.2,10.0,20,71.4$ and 91.7 respectively. For chronic 
injury patients the scores were $71.5,10.4,70.8,18.7$, and 89.8 respectively. Comparing the acute and chronic patients, the LEFS, Marx Activity score, custom LEFS, and proximal hamstring score were not statistically significant $(P=0.22, P=0.6, P=0.72, P=0.6$, respectively). The acute injury patients did have a greater custom Marx score $(P=0.001)$. Postoperatively, 5 patients $(9.6 \%)$ had burning pain or numbness in the posterior thigh or foot and 25 (48 \%) had at least some discomfort sitting. Thirty-five patients $(67 \%)$ reported they could participate in strenuous activities at their latest follow-up. All patients estimated their strength recovery at $\geq 75 \%$.

Conclusion: This is the first study to use subjective validated outcome scales in patients who have had repair of proximal hamstring avulsions. Results of this study indicate successful outcomes for both acute and chronic repairs although the acute repairs had higher functional and hamstring scores, and estimated hamstring strength.

\section{Study Design: Level IV - Retrospective Case Series}




\section{Introduction}

Proximal hamstring ruptures are increasingly diagnosed in both young and middle-aged

patients. Despite the fact that this subset of hamstring injuries is less common than the myotendinous junction strains, it often results in more debilitating outcomes if left untreated in active patients. ${ }^{1,12,13}$ Until recently, proximal hamstring ruptures remained largely unrecognized by treating physicians. In fact, delayed diagnosis of proximal hamstring avulsion has been reported in several studies, showing that patients often consult with various health care professionals, including other orthopaedic surgeons, before receiving appropriate treatment. ${ }^{9,17}$

Non-operative management of proximal hamstring injuries is reserved for one or two tendon ruptures with $\leq 2 \mathrm{~cm}$ of retraction. ${ }^{6}$ Conservative treatment is less successful for more significant injuries and acute surgical intervention is recommended for 1) two tendon avulsion with $>2 \mathrm{~cm}$ of retraction, and 2) complete three tendon tears regardless of the extent of retraction..$^{6,9,14,15}$ Several studies have shown that acute surgical repair results in higher patient satisfaction, more frequent return to sport at the pre-injury level, equivalent isokinetic strength testing, and low rates of complications. ${ }^{6,17}$ Acute surgical repair is defined as operative re-approximation of the avulsed tendons within 4 weeks of the injury, while chronic repairs are those treated after 4 weeks from the index trauma. ${ }^{6,9,14}$ In contrast to the easier surgical mobilization of acute injuries, chronic repair tends be more surgically demanding due to the need for sciatic neurolysis and increased dissection of the retracted tendons, both of which result in less favorable outcomes.

Despite the increased surgical treatment of proximal hamstring injuries, there exists a paucity of data supporting operative management. While the literature does demonstrate that operative treatment of hamstring avulsions results in higher patient satisfaction, rates of return to play, and isokinetic strength testing, these studies are often challenged due to the relatively small number of 
patients..$^{4,5,7,8,10,14,17,18}$ Furthermore, a recent systematic review of the literature on treatment of proximal hamstring ruptures indicated that there are only a few studies that have analyzed this injury (either acute or chronic) with validated outcome measures. ${ }^{9}$

Therefore, the purpose of this study is to assess post-surgical outcomes in active recreational athletes after primary repair of acute and chronic proximal hamstring tears. In contrast to the majority of previously published studies that are limited to case reports and small series, our study is comprised of a larger cohort of patients assessed with validated outcome scores (Lower Extremity Functional Scale and Marx Activity Scale). We hypothesized that surgical treatment of both acute and chronic proximal hamstring avulsion injuries would result in improved patient outcomes using a hamstring-specific questionnaire and that operative repair of these injuries results in excellent results with a high level of patient satisfaction, pain relief, and return to function.

\section{Materials and Methods}

Between 2007 and 2010, a total of 63 patients were treated operatively for proximal hamstring rupture by two senior surgeons (—) at separate institutions. Institutional review board approval was obtained from both institutions. Patient operative reports were initially retrieved from institution records for patients who had undergone proximal hamstring repair. Proximal hamstring injuries were predominantly complete avulsion of the biceps femoris, the semitendinosus, and the semimembranosus tendons from the ischial tuberosity although other injuries included 1 or 2 tendon ruptures that failed nonoperative treatment and 1 ischial tuberosity bony avulsion.

Medical records were retrospectively reviewed and demographic information, clinical examination findings, and surgical documentation were collected. A phone survey was administered to obtain functional outcome scores. The phone survey contained the Lower Extremity Functional Scale 
$\left(\right.$ LEFS) ${ }^{2}$, the Marx Activity Scale ${ }^{11}$, custom Marx Activity score (out of 20), custom LEFS score (out of 80 ), a combined custom score to encompass the proximal hamstring score (out of 100), and subjective questions concerning neurovascular issues and patient history (Appendix 1). The custom scores were adapted from other validated questionnaires to utilize the same scoring methods, but with activities and functions specific to the hamstring. The subjective questionnaire included questions related to pain, satisfaction, and hamstring related function. It also asked the number of physician visits prior to diagnosis for surgical intervention. The sum of the two questionnaires (custom Marx and custom LEFS) made up the proximal hamstring score.

Inclusion criteria included patients with acute ( $<4$ weeks from injury to surgery) and chronic ( $>4$ weeks from injury to surgery) proximal hamstring tears that had a minimum of 12 months postoperative follow-up. Exclusion criteria included any patient with less than 1 year follow-up or who were unable to complete the postoperative functional questionnaire.

Patients who responded that they injured their hamstring participating in sports-related activities were asked 5 additional questions to measure their return to sport and post-operative function with sports activities (Appendix 1).

Of the 63 patients who met the inclusion criteria, 52 patients completed the questionnaires (83\%) and were included in the analysis. Twenty-six patients were female and 26 were male. The average age at the time of surgery was 47.7 years (range: $17-66)$.

\section{Presenting Symptoms/Mechanism of Injury}

The mechanism of injury in 27 patients was due to eccentric hip flexion and knee extension in the ipsilateral knee typically caused by a slip and fall accident. One patient presented with a complete avulsion, after trying to lift his motorcycle from the ground with his hip flexed and knee locked. Another 
patient's injury was due to trauma. Twenty-three patients were injured during sports participation. All patients presented with hamstring weakness ranging from significant weakness against gravity to mild weakness with resistance testing. Additional complaints included pain and discomfort in the posterior thigh. For most patients, pain was present at rest and with activity. Patients also had difficulty walking and sitting, with either instability or poor leg control in the affected hamstring. At presentation, most patients walked with a stiff-legged gait pattern to avoid hip and knee flexion. Acute hamstring injuries presented with a large hematoma in the posterior thigh, with edema and ecchymosis overlying the site of injury and extending distally. A palpable defect or a distal bulge caused by the retracted tendons was also present in most patients. For acute patients, a palpable defect was not always easily established due to excessive tenderness and edema. Chronic hamstring injury patients had similar symptoms as acute patients, but with more complaints of neuralgia and sciatica-type symptoms.

\section{Diagnosis}

A large number of patients in our cohort were referred from other orthopedic surgeons, physical therapists, neurologists and other specialties with the diagnosis determined, while several patients were referred before being properly diagnosed with a proximal hamstring rupture. Hamstring sprain/strain or microtear was often the incorrect primary diagnosis subsequently followed by unsuccessful nonoperative treatment for those patients with chronic tears.

The diagnosis of proximal hamstring rupture was confirmed by clinical examination and MRI. The patient was examined in a supine position to assess hip flexion which is often limited due to pain and popliteal angle which can be decreased compared to the contralateral side and reproduce proximal pain (different than a common mid-muscle belly strain).. Next, the patient was examined in the prone position to assess for tenderness and a palpable defect, and was asked to contract the hamstring with the knee flexed also at 15, 45, and 90 degrees. The peroneal branch of the sciatic nerve was assessed by 
testing foot and ankle strength and a sensory examination of the posterior thigh, calf, and foot. It is important to determine any nerve damage as a result of a stretch injury (neurapraxia), as this can cause some residual postoperative weakness. The MRI scans included sagittal, coronal, and axial views of the involved and uninvolved limb from the pelvis to the knees. Retraction of the hamstring muscles from the ischial tuberosity and type of hamstring tear were noted based on these images.

\section{Surgical technique and rehabilitation}

The surgical technique utilized in this study has been previously described. ${ }^{6}$ Briefly, the patient was placed prone with all bony prominences well padded and the trunk in slight flexion. A transverse incision in the gluteal crease inferior to the ischial tuberosity was used. Loop magnification and a headlight were routinely used to ensure protection of the posterior femoral cutaneous nerve and visualization of the ischial tuberosity for anchor placement. The sciatic nerve was only dissected free in cases of chronic injury with scarring or preoperative sciatic nerve symptoms. Once the ruptured tendon was visualized, freed up from scar, and debrided, it was tagged for repair. The ischial tuberosity was then identified and cleared off with curved and straight currettes or a periosteal elevator. It is important that no motorized device is used to roughen the bone in order to protect from injury to the sciatic nerve. The conjoined hamstring tendons wasrepaired together to bone with bioabsorbable suture anchors (Arthrex $3.0 \mathrm{~mm}$ BiosutureTak with number 2 Fiberwire, Naples, Fl). Anchors were placed in the configuration of an $\mathrm{X}$ using a total of five anchors (Figure 1). Sutures were passed through tendons using horizontal mattress sutures from inferior to superior and are tied down from superior to inferior with the knee flexed at 30 degrees. The affected leg was then placed in a hip orthosis that restricts hip flexion to a range of to 30 to 40 degrees. Patients were maintained on aspirin for 4 weeks postoperatively for DVT prophylaxis. 
The patient ambulated on crutches with toe-touch weight bearing for the first 2 weeks. Weight bearing was advanced to full by 4 weeks with continued use of crutches until 6 weeks. The brace was removed between 6 and 8 weeks postoperative. Passive hip range of motion (ROM) was begun with a therapist at 2 weeks while active hip flexion was started at 4 weeks. Isotonic (6 weeks) and isokinetic (8 weeks) strengthening and aqua therapy were initiated with progression of core pelvic and closed chain exercises. Dry land training and sport specific training were initiated at 12 weeks with return to full sports participation between 5 to 8 months.

\section{Statistical Analysis:}

The R.2.13 (Bell Laboratories; Murray Hill, NJ) software was used for statistical analysis. The Wilcoxon test was also used to analyze the outcome measures because the data was not normally distributed The outcome scores that were analyzed were the LEFS, Marx, custom LEFS, custom Marx and the combined custom hamstring score.

\section{Results}

The mean follow-up in our study was 33 months (range: 12-76 months). In 31 of the patients the right leg was affected, and in 21 the left leg was affected. There were a total of 26 women and 26 men. The mechanism of injury in 28 patients was due to eccentric hip flexion and knee extension in the ipsilateral knee typically caused by a slip and fall accident. One patient presented with a complete avulsion, after trying to lift his motorcycle from the ground. In 23 patients hamstring injuries were sports related. The three most common sports in which injuries occurred were waterskiing accidents ( $\mathrm{n}$ $=6)$, downhill snow skiing $(n=4)$ and running $(n=6)$. Sports related hamstring injuries were described due to eccentric hip flexion and knee extension. One of the sport-related injury patients reported pain and a "popping" noise after pivoting while running. Blunt trauma to the hamstring region was reported in only one patient (Table 1). 
The majority of cases (38 of 52) were complete avulsion of the hamstring muscles. There were 12 patients with 2 tendon tears, oneof the two tendon tear patients also had a bony avulsion of the ischial tuberosity. There were 2 patients with a 1 tendon tear that failed nonoperative treatment who went on to require surgical repair. There were no surgical complications or re-operations in our study cohort .However, it should be noted that one patient who declined to participate in this study developed a postoperative sciatic nerve palsy due to surgical retraction during the repair. A number of patients complained of postoperative incisional numbness $(\mathrm{N}=20)$ while few complained of posterior thigh numbness $(\mathrm{N}=5)$ (see results below). One patient developed a lower extremity DVT and was placed on anti-coagulation for 3 months.

\section{Outcome measures:}

Overall, of the 52 patients in our cohort, 51 or $98 \%$ were satisfied with their outcome following surgery and scored an average of 10.2 (range: 1-16) on the Marx Activity Scale and 75.2 out of 80 (range: 50-80) on the LEFS, which is a highly functional score. Outcome measures between acute and chronic patients were compared. Forty patients were characterized as having acute repairs and 12 patients had chronic repairs. Comparing the acute and chronic patients, the LEFS, Marx Activity score, custom LEFS, and proximal hamstring score were not statistically significant $(P=0.22, P=0.6, P=0.72, P=0.6$, respectively). The acute injury patients did have a greater custom Marx score $(P=0.001)$ (Table 2$)$. Out of the 52 patients, $37 \%(n=19)$, were misdiagnosed or treated unsuccessfully by more than 1 health care practitioner before consulting with either of the senior authors (mean: 1.5, range, 1 to 4 ). The majority of these patients were diagnosed with a hamstring strain without an MRI scan, as a complete avulsion was not in the initial differential diagnosis. Thirty patients $(58 \%)$ consulted a physician including the senior surgeons within one week of their hamstring injury. 
The majority of patients in our study responded that they never experienced postoperative loss of leg control, muscle cramps, or having their affected leg get in the way of normal activities (Table 3). Additionally, 35 patients (67\%) reported they could participate in strenuous activities at their latest follow-up. Strenuous activity referred to the patient's own subjective ability to be active, therefore quantifying an objective level of activity could not be determined. All patients estimated their strength recovery at $\geq 75 \%$. Strength recovery was based on a categorical basis, and was part of the subjective portion of the hamstring questionnaire. According to the patient, strength was estimated to be around $25 \%, 50 \%, 75 \%$ or $100 \%$ when compared to their opposite hamstring/leg. In total, 28 patients reported their recovery at $100 \%$ and 24 reported it at $75 \%$. Chronic repair patients had a less estimated mean strength, (mean: 88, SD: 13), than acute repair patients, (mean: 89, SD: 13).There was no statistically significant difference when these two groups were compared $(P=0.77)$ (Table 2).

Neuralgia symptoms, characterized as "tingling or burning in the back of the thigh, or foot" in the proximal hamstring questionnaire was present in 5 patients (9.6\%) (Table 2). These 5 patients had persistent posterior thigh numbness due to injury to the posterior femoral cutaneous nerve during the surgical repair that was not resolved at the time of the latest follow-up. Three of the five patients (60\%) were chronic injuries and 2 were acute. Of the 5 patients with true posterior thigh neuralgia $2(40 \%)$ patients described their neuralgia occurred at all levels of activity (at rest, during normal activity, during strenuous activity). No patients complained of postoperative numbness in the foot. An additional 20 patients complained of persistent postoperative incisional numbness only which was not deemed to be subjectively symptomatic by the patients and thus there were a total of 25 patients included in the "neuralgia" group. Of these 20 , a total of 16 patients (80\%) were acute repairs and 4 were chronic repairs. The other 27 patients responded that they had no neuralgia or sciatica-type symptoms. Patients who responded "Never" to both neuralgia questions were compared to patients who responded that they had symptoms at some level of activity (either in the thigh, foot, or both). The 
average score differences for the LEFS, custom Marx, custom LEFS and proximal hamstring scores for the two groups were not statistically significant (Table 2). Patients without neuralgia symptoms had a greater estimated mean strength than patients with neuralgia symptoms; but there was no statistical significant difference when these two groups were compared (Table 2). In addition to neuralgia symptoms, the length of time the patient could sit comfortably was asked. Twenty-seven patients (52\%) responded that they had no restriction with sitting. Of the $52 \%$ of the patients which did describe sitting pain, the majority of these occurred on a harder surface and most patients stated that sitting on a softer, warmer surface reduced pain and discomfort.

\section{Return to Sports}

There were a total of 23 patients who injured their hamstring during a sports activity (Table 1 ). Patients returned to sport (injury related sport or other sport) at an average of 6.6 months (SD: 2.5, range: 3 to 15$)$. Sixteen patients $(69.6 \%)$ returned to the sport in which they injured their hamstring. In fact, four running patients and one professional baseball player returned immediately back to the their sport at an average of 5.2 months, hence return to sport and return sport of injury are the same duration (Table 4).The other 11 patients eventually returned to their specific sport of injury after their initial return to another sportat an average of 4.4 months (SD: 1.9, range: 2 to 7). All 6 patients who injured their hamstring while waterskiing did not return to that specific sport due to concerns of reinjuring or physicians' advice to not participate in that activity. One patient did not return to high school football because the season was over and he had graduated from school. However, all of these patients did return to other sports (Table 4).

The patients were asked to rate themselves on a scale from 1 to 10 on how strenuously/actively they could play that sport. The 5 patients who returned right back to their sport of injury had an average of 6 out of 10 (range: 5 to 8).The remaining 18 patients who returned to sport (not sport of injury) also 
had an average of 6 out of 10 (SD: 1, range: 4 to 8 ). The twelve patients who eventually returned to their sport of injury had a moderate level of activity, rating themselves 7 out of 10 (SD 0.9, range 6 to 9) (Table 4).

Two additional questions were asked regarding strenuously/activity prior to injury and at last follow-up. Prior to injury, patients reported subjectively higher levels of performance in sports, (average: 9, SD: 1, range: 7-10) when compared to last follow up (average: 8.3, SD: 1.1, range: 6-10) (Table 4). Analysis using the Wilcoxon test indicated that these two scores were significantly different $(P=0.006)$. Despite statistical significance, all patients reported that they were satisfied with their performance and activity levels after surgery. Furthermore, it should be noted that two of our patients were avid marathon runner prior to injury and one patient was a professional baseball player (Table 4). At last follow up both runners have been able to participate in marathons without complaints, and the professional baseball player was able to return to his pre-injury major league level and was satisfied with his function and performance.

\section{Discussion}

The overall results of proximal hamstring repairs reported in the literature have been quite favorable indicating surgical treatment is most likely more beneficial than nonoperative treatment. There have been several large series reporting their results mainly looking at strength testing ${ }^{18}$ and routine return to function ${ }^{19}$. However, no studies have used any validated functional outcome scales to assess their results. In 2008, Wood et al used isotonic strength testing (84\%) and hamstring endurance (89\%) at 1 year follow-up to assess their results in 21 patients after hamstring repair. ${ }^{19}$ Also in 2008, Sarimo et al used a fairly arbitrary 4 category rating system to evaluate 41 patients at a mean of 37 months. ${ }^{18}$ They determined using this system that 19 patients had an excellent result and 10 patients 
had a good result. The 7 patients with poor results underwent their repair at an average of 11.7 months and they concluded that chronic repairs had poorer results than acute repairs.

Recently, Birmingham et al reported on functional outcomes following proximal hamstring rupture with 23 patients ( 9 acute, 14 chronic) using a non-validated subjective questionnaire, functional testing, and isokinetic testing. ${ }^{3}$ Their results showed that post-operative hamstring strength was approximately $90 \%$ compared to the uninjured side. From the subjective questionnaire, eighteen of their patients had excellent results. In addition, there were no significant correlations between the post-operative isokinetic data and acute versus chronic repair, or age of the patient. The biggest limitation of their study was that the questionnaire used was not a validated outcome measurement, even though several questions had significant correlations between post-operative strength and endurance.

Our study used validated outcomes, the Marx Activity scale and the LEFS, to determine subjective results following proximal hamstring repair. The patients scored an average of 10.4 on the Marx Activity Scale and 76 out of 80 on the LEFS, which is a highly functional score. Results of this study indicate excellent return to function and activity as well as return of hamstring strength.

The mechanism of injury for proximal hamstring ruptures has been well documented. ${ }^{6,7,16}$ Patients who sustain a violent eccentric contraction of the hamstring during knee extension and hip flexion typically feel a sharp pop or pull near the buttocks. They classically present with significant ecchymosis about the posterior thigh, difficulty ambulating, and significant sitting pain. While the most common and well known mechanism of injury is water skiing, ${ }^{6,16,17}$ the injury may occur in other sports and commonly occurs during non-athletic slip and falls. In our series only 23 of 52 cases (44\%) were sports related which indicates that one's clinical suspicion for these injuries should be high in the everyday patients who sustain an injury with this mechanism. While mid-hamstring pain is often 
associated with a hamstring strain, proximal pain and the above noted exam should lead to a high clinical suspicion for a complete rupture which can be confirmed on MRI scan. Studies have found that acute repair leads to improved results and an easier repair, while late repair often requires specialized skill for surgical repair due to higher risks (tendon retraction and nerve injury) and lower functional outcomes. $^{4,6,9,16,18}$

As with most if not all tendon injuries, early repair of the tendon tear generally results in more favorable outcomes. In general, acute management is considered when the repair is performed within 4 weeks of injury. In this series only 12 of the 52 patients (23\%) underwent repair of a chronic tear. Despite some series that found no significant differences in results of treatment of acute and chronic repairs, ${ }^{18}$ others have found residual deficits with chronic repair ${ }^{5}$ and inferior results ${ }^{19}$. The results of this study do not show a significant difference in the Marx Activity scale. The functional results for the LEFS while notstatistically significant were higher for the 40 patients treated acutely when comparing the 12 patients treated with chronic tears. However, a Wilcoxon test indicated that patients treated with acute tears had greater custom Marx scores. Although the custom Marx is not a validated score, based on these results and our experience we recommend if surgery is being considered that early surgical repair be performed. More chronic tears are more difficult to mobilize and place the sciatic nerve at higher risk of injury during repair.

Sciatic nerve paresthesias are a common complaint for patients who are at least 12 months out of surgery. From our cohort, nearly half of all patients had some degree of neuralgia symptoms, although only 5 patients had true neuralgia in the posterior thigh. These symptoms place a potential risk for decreased functional outcome scores. Our study indicated that patients without neuralgia symptoms had improved but not statistically significant LEFS, Marx, custom LEFS, custom Marx, and proximal hamstring scores. Therefore, even though chronic patients tend to have a higher risk of injury 
during repair, physicians should be aware that acute and chronic injuries alike can have postoperative nerve problems. Sitting pain is another potential complication after surgical repair although nearly all patients who sustain a complete proximal hamstring rupture complain of acute sitting pain after their injury. However half of the patients in this study stated that had continued postoperative sitting discomfort generally due to the incision location over the ischial tuberosity.

As with any surgical treatment there are complications associated with surgical repair. The three main structures at risk are the posterior femoral cutaneous (PFC) nerve, the inferior gluteal nerve (IGN), and the sciatic nerve. The PFC nerve is at risk during the approach and injury presents with numbness over the posterior thigh. The IGN can be injured during gluteal muscle retraction also during the surgical approach. The sciatic nerve is at risk during identification and mobilization of the detached conjoined tendon which may be scarred around the sciatic nerve. In addition, since the sciatic nerve is in close proximity to the ischial tuberosity, it can be injured from retraction during exposure of the tuberosity. Five of the patients in this study $(9.6 \%)$ had true postoperative neuralgia symptoms, all from injury to the PFC.

There are several weaknesses of this study. This is a retrospective study where phone interview was used to complete questionnaires and despite obtaining postoperative subjective functional scores, there are no preoperative scores to compare the outcomes. In addition, there is no control group of non-surgical treatment to compare the outcomes to the surgical repair group. Eleven patients (18\%) were lost to follow-up so their data was not utilized in this study, although this rate is reasonable for a retrospective study. Other studies have looked at objective strength testing, which was not assessed in this study. This study includes a heterogeneous population with a mix of acute and chronic repairs as well as patients with complete ruptures and high grade partial tears.

\section{Conclusion}


This is the first study to use subjective validated outcome scales in patients who have had repair of proximal hamstring avulsions. Results of this study indicate successful outcomes for both acute and chronic repairs although the acute repairs had slightly higher but not significant functional and hamstring scores, and estimated hamstring strength. Further studies need to be performed to assess the prospective subjective outcomes as well as compare patients with and without surgical repair. 


\section{$\underline{\text { References }}$}

1. Beltran L, Ghazikhanian V, Padron M, Beltran J. The proximal hamstring muscle-tendon-bone unit: A review of the normal anatomy, biomechanics, and pathophysiology. Eur J Radiol 2011;Apr 25. [Epub ahead of print]

2. Binkley JM, Stratford PW, Lott SA, Riddle DL. The Lower Extremity Functional Scale (LEFS): scale development, measurement properties, and clinical application. North American Orthopaedic Rehabilitation Research Network.PhysTher. 1999;79(4):371-83.

3. Birmingham P, Muller M, Wickiewicz TL, Cavanaugh J, Rodeo S, Warren RF. Functional outcome after repair of proximal hamstring avulsions.J Bone Joint Surg Am.2011;19:1819-26.

4. Brucker PU, Imhoff AB. Functional assessment after acute and chronic complete ruptures of the proximal hamstring tendons. Knee Surg Sports Traumatol Arthrosc2005;13:411-418.

5. Chakravarthy J, Ramisetty N, Pimpalnerkar A, Mohtadi N. Surgical repair of complete proximal hamstring tendon ruptures in water skiers and bull riders: a report of four cases and review of the literature. Br J Sports Med2005;39:569-572.

6. Cohen SB, Bradley JP. Acute proximal hamstring rupture. J Am Acad Orthop Surg 2007;15:350355.

7. Cross MJ, Vandersluis R, Wood D, Banff, M. Surgical repair of chronic complete hamstring tendon rupture in the adult patient. Am J Sports Med1998;26:785-788.

8. Folsom GJ, Larson CM. Surgical treatment of acute versus chronic complete proximal hamstring ruptures: results of a new allograft technique for chronic reconstructions. Am J Sports Med2008;36:104-109.

9. Harris JD, Griesser MJ, Best TM, Ellis TJ. Treatment of proximal hamstring ruptures - a systematic review. Int J Sports Med 2011;32:490-95.

10. Klingele KE, Sallay PI. Surgical repair of complete proximal hamstring tendon rupture. Am J Sports Med2002;30:742-747.

11. Marx RG, Stump TJ, Jones EC, Wickiewicz TL, Warren RF. Development and Evaluation of an Activity Rating Scale for Disorders of the Knee. Am J Sports Med 2001;29:213-218.

12. Mendiguchia J, Alentorn-Geli E, Brughelli M. Hamstring strain injuries: are we heading in the right direction? Br J Sports Med 2011;Jun 15.

13. Mendiguchia J, Brughelli M. A return-to-sport algorithm for acute hamstring injuries. Phys Ther Sport 2011;12:2-14. 
14. Orava S, Kujala UM. Rupture of the ischial origin of the hamstring muscles. Am J Sports Med1995;23:702-705.

15. Orchard J, Best TM. The management of muscle strain injuries: an early return versus the risk of recurrence. Clin J Sport Med2002;12:3-5.

16. Sallay PI, Ballard G, Hamersly S, Schrader M. Subjective and functional outcomes following surgical repair of complete ruptures of the proximal hamstring complex. Orthopedics 2008;31:1092..

17. Sallay PI, Friedman RL, Coogan PG, Garrett WE. Hamstring muscle injuries among water skiers. Functional outcome and prevention. Am J Sports Med1996;24:130-136.

18. Sarimo J, Lempainen L, Mattila K, Orava S. Complete proximal hamstring avulsions: a series of 41 patients with operative treatment. Am J Sports Med2008;36:1110-1115.

19. Wood DG, Packham I, Trikha SP, Linklater J.Avulsion of the proximal hamstring origin.J Bone Joint Surg Am2008;11:2365-74. 
Table 1: Mechanism of Injury

\begin{tabular}{|l|l|}
\hline Mechanism of Injury & Patients \\
\hline Not Sports Related & 29 \\
\hline Eccentric Hip Flexion, Knee Extension & 27 \\
\hline Other & \\
\hline Blunt Trauma & 1 \\
\hline Hip Flexion, Knee locked & 1 \\
\hline & \\
\hline Sports Related & 23 \\
\hline Waterskiing & 6 \\
\hline Running & 6 \\
\hline Down Hill Skiing & 4 \\
\hline Softball & 2 \\
\hline Baseball & 1 \\
\hline Football & 2 \\
\hline Tennis & 2 \\
\hline
\end{tabular}

Table 2: Outcome Results

* Indicates Statistical Significance

\begin{tabular}{|c|c|c|c|c|c|c|c|}
\hline $\begin{array}{l}\text { Outcome } \\
\text { Measures }\end{array}$ & Patients & $\begin{array}{l}\text { LEFS Mean } \\
\text { and Range }\end{array}$ & $\begin{array}{l}\text { Marx Mean } \\
\text { and Range }\end{array}$ & $\begin{array}{l}\text { Custom LEFS } \\
\text { Mean and Range }\end{array}$ & $\begin{array}{l}\text { Custom Marx } \\
\text { Mean and Range }\end{array}$ & $\begin{array}{l}\text { Hamstring Score } \\
\text { Mean and Range }\end{array}$ & $\begin{array}{l}\text { Estimated } \\
\text { Strength Mean }\end{array}$ \\
\hline Acute Repairs & 40 & $\begin{array}{l}76.2 \text { (Range: } \\
62 \text { to } 80 \text { ) }\end{array}$ & $\begin{array}{l}10.0 \text { (Range: } 1 \\
\text { to } 16 \text { ) }\end{array}$ & $\begin{array}{l}71.4 \text { (Range: } 48 \\
\text { to } 80 \text { ) }\end{array}$ & $\begin{array}{l}20 \text { (all pts had } \\
\text { same score) }\end{array}$ & $\begin{array}{l}91.7 \text { (Range: } 82 \\
\text { to } 100 \text { ) }\end{array}$ & 88.6 \\
\hline $\begin{array}{l}\text { Chronic } \\
\text { Repairs }\end{array}$ & 12 & $\begin{array}{l}71.5 \text { (Range: } \\
50 \text { to } 80 \text { ) }\end{array}$ & $\begin{array}{l}10.4 \text { (Range: } 2 \\
\text { to } 16 \text { ) }\end{array}$ & $\begin{array}{l}70.8 \text { (Range: } 47 \\
\text { to } 80 \text { ) }\end{array}$ & $\begin{array}{l}18.7 \text { (Range: } 12 \\
\text { to } 20)^{*}\end{array}$ & $\begin{array}{l}89.6 \text { (Range: } 67 \\
\text { to } 100 \text { ) }\end{array}$ & 87.5 \\
\hline $\begin{array}{l}\text { Statistical } \\
\text { Analysis of } \\
\text { Acute and } \\
\text { Chronic }\end{array}$ & & $P=0.22$ & $P=0.6$ & $P=0.72$ & $P=0.001$ & $P=0.6$ & $P=0.77$ \\
\hline
\end{tabular}


Patients

\begin{tabular}{|c|c|c|c|c|c|c|c|}
\hline $\begin{array}{l}\text { Patients with } \\
\text { Neuralgia } \\
\text { Symptoms }\end{array}$ & 25 & $\begin{array}{l}74.6 \text { (Range: } \\
50 \text { to } 80 \text { ) }\end{array}$ & $\begin{array}{l}9.0 \text { (Range: } 2 \\
\text { to } 16 \text { ) }\end{array}$ & $\begin{array}{l}69.64 \text { (Range: } 47 \\
\text { to } 80 \text { ) }\end{array}$ & $\begin{array}{l}19.6 \text { (Range: } 16 \\
\text { to } 20 \text { ) }\end{array}$ & $\begin{array}{l}89.3 \text { (Range: } 67 \\
\text { to } 100 \text { ) }\end{array}$ & 91 \\
\hline $\begin{array}{l}\text { Patients w/o } \\
\text { Neuralgia } \\
\text { Symptoms }\end{array}$ & 27 & $\begin{array}{l}76.0 \text { (Range: } \\
62 \text { to } 80 \text { ) }\end{array}$ & $\begin{array}{l}11.3 \text { (Range: } 1 \\
\text { to } 16)\end{array}$ & $\begin{array}{l}73.6 \text { (Range: } 48 \\
\text { to } 80 \text { ) }\end{array}$ & $\begin{array}{l}19.9 \text { (Range: } 12 \\
\text { to } 20 \text { ) }\end{array}$ & $\begin{array}{l}93.0 \text { (Range: } 68 \\
\text { to } 100 \text { ) }\end{array}$ & 86 \\
\hline $\begin{array}{l}\text { Statistical } \\
\text { Analysis of } \\
\text { Patients with } \\
\text { and without } \\
\text { Neuralgia } \\
\text { Symptoms }\end{array}$ & & $P=0.33$ & $P=0.10$ & $P=0.29$ & $P=0.53$ & $P=0.26$ & $P=0.24$ \\
\hline
\end{tabular}

Table 3: Questionnaire Results

\begin{tabular}{|l|c|c|c|c|c|c|}
\hline & Patients & & & & \\
\hline Hamstring Questionnaire & & & & & \\
\hline & Never & $\begin{array}{l}\text { Less than 1 time } \\
\text { per month } \\
\text { per month }\end{array}$ & $\begin{array}{l}\text { One time in } \\
\text { a week }\end{array}$ & $\begin{array}{l}2-3 \text { times in } \\
\text { a week }\end{array}$ & Daily \\
\hline Get in the way of normal activities & 28 & 10 & 8 & 4 & 2 & 0 \\
\hline Muscle Cramps & 30 & 5 & 11 & 5 & 1 & 0 \\
\hline Loss of Leg control & 46 & 3 & 3 & 0 & 0 \\
\hline
\end{tabular}

Table 4: Return to Sport Data

\begin{tabular}{|c|c|c|c|c|c|c|}
\hline Sport & $\begin{array}{l}\text { Return to Sport } \\
\text { (months) }\end{array}$ & $\begin{array}{l}\text { Performance } \\
\text { Scale (1-10) }\end{array}$ & $\begin{array}{l}\text { Return to Sport } \\
\text { of Injury } \\
\text { (months) }\end{array}$ & $\begin{array}{l}\text { Performance } \\
\text { Scale (1-10) }\end{array}$ & $\begin{array}{l}\text { Performance in } \\
\text { sport prior to } \\
\text { injury (1-10) }\end{array}$ & $\begin{array}{l}\text { Performance } \\
\text { at last follow- } \\
\text { up (1-10) }\end{array}$ \\
\hline Running & 6 & 4 & 8 & 6 & 8 & 8 \\
\hline
\end{tabular}




\begin{tabular}{|c|c|c|c|c|c|c|}
\hline Running* & 3 & 5 & 3 & 5 & 10 & 8 \\
\hline Running* & 6 & 5 & 6 & 5 & 8 & 8 \\
\hline Running & 6 & 7 & 9 & 9 & 10 & 10 \\
\hline Running* & 7 & 8 & 7 & 8 & 10 & 10 \\
\hline Running* & 4 & 7 & 4 & 7 & 9 & 10 \\
\hline Baseball* & 6 & 6 & 6 & 8 & 10 & 9 \\
\hline Tennis & 8 & 6 & 10 & 7 & 9 & 7 \\
\hline Tennis & 10 & 8 & 15 & 7 & 10 & 10 \\
\hline Softball & 6 & 4 & 12 & 6 & 9 & 7 \\
\hline Softball & 6 & 5 & 12 & 7 & 8 & 7 \\
\hline Football & 6 & 6 & did not return & N/A & 10 & 7 \\
\hline Football & 5 & 7 & 12 & 8 & 10 & 8 \\
\hline Down Hill Skiing & 7 & 7 & 12 & 8 & 10 & 8 \\
\hline Down Hill Skiing & 6 & 5 & 12 & 6 & 7 & 6 \\
\hline Down Hill Skiing & 8 & 6 & 10 & 7 & 8 & 8 \\
\hline Down Hill Skiing & 7 & 7 & 11 & 7 & 10 & 9 \\
\hline Waterskiing & 8 & 6 & did not return & $\mathrm{N} / \mathrm{A}$ & 7 & 6 \\
\hline Waterskiing & 6 & 5 & did not return & N/A & 9 & 7 \\
\hline Waterskiing & 6 & 7 & did not return & $\mathrm{N} / \mathrm{A}$ & 8 & 8 \\
\hline Waterskiing & 15 & 5 & did not return & N/A & 10 & 6 \\
\hline Waterskiing & 3 & 6 & did not return & N/A & 10 & 10 \\
\hline Waterskiing & 6 & 6 & did not return & N/A & 8 & 8 \\
\hline
\end{tabular}

*Patients who returned directly to sport of injury 
Appendix 1. Proximal Hamstring Questionnaire with LEFS, Marx Activity Score, Custom LEFS, Custom Marx and subjective questions.

Figure 1: Picture depicting 5 anchor repair of the proximal hamstring on the ischial tuberosity (from Cohen SB, Bradley JP. Acute proximal hamstring rupture. J Am Acad Orthop Surg2007;15:350-355. Reprint permission required 